\title{
Ice shelf flexures modeled with a 2-D elastic flow line model
}

\section{Y. V. Konovalov}

Department of Mathematics, National Research Nuclear University "MEPhl", Kashirskoe shosse, 31, 115409 Moscow, Russia

Received: 1 August 2011 - Accepted: 6 October 2011 - Published: 19 October 2011

Correspondence to: Y. V. Konovalov (yu-v-k@yandex.ru)

Published by Copernicus Publications on behalf of the European Geosciences Union.

Ice shelf flexures modeled with a 2-D elastic flow line model

Y. V. Konovalov

\section{Title Page}

\section{Abstract}

Conclusions
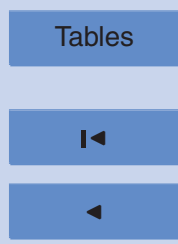

Back
Introduction

References

Figures

$\rightarrow$

$>$

Close
Full Screen / Esc

Printer-friendly Version

Interactive Discussion 


\section{Abstract}

Ice shelf flexures modeling was performed using a 2-D finite-difference elastic model, which takes into account sub-ice-shelf sea water flow. The sub-ice water flow was described by the wave equation for the sub-ice-shelf pressure perturbations (Holdsworth

5 and Glynn, 1978). In the model ice shelf flexures result from variations in ocean pressure due to changes in prescribed sea levels. The numerical experiments were performed for a flow line down one of the fast flowing ice streams of the Academy of Sciences Ice Cap. The profile includes a part of the adjacent ice shelf. The numerical experiments were carried out for harmonic incoming pressure perturbations $P^{\prime}$ and the ice shelf flexures were obtained for a wide spectrum of the pressure perturbations frequencies, ranging from tidal periods down to periods of a few seconds $(0.004 .0 .02 \mathrm{~Hz})$. The amplitudes of the ice shelf deflections obtained by the model achieve a maxima at about $T \approx 165 \mathrm{~s}$ in concordance with previous investigations of the impact of waves on Antarctic ice shelves (Bromirski et al., 2010). The explanation of the effect is found 15 in the solution of the corresponding eigenvalue problem revealing the existence of a resonance at these high frequencies.

\section{Introduction}

Tides and ocean swells produce ice shelf bends and, thus, can lead to break-up of sea ice in the marginal zone (Holdsworth and Glynn, 1978; Goodman et al., 1980; Wadhams, 1986; Squire et al., 1995; Meylan et al., 1997; Turcotte and Schubert, 2002) and to ice-shelf rift propagation. Strong correlations between rift propagation rate and ocean swells impact has however, yet to be revealed (Bassis et al., 2008), and it is not clear to what degree rift propagation can potentially be triggered by tides and ocean swells. Nevertheless, the impact of tides and ocean swells is the part of the total force (Bassis et al., 2008) that produces sea ice calving processes in ice shelves (MacAyeal et al., 2006). Thus, the understanding of vibrating processes in ice shelf is important at

\section{Ice shelf flexures modeled with a 2-D elastic flow line model}

Y. V. Konovalov

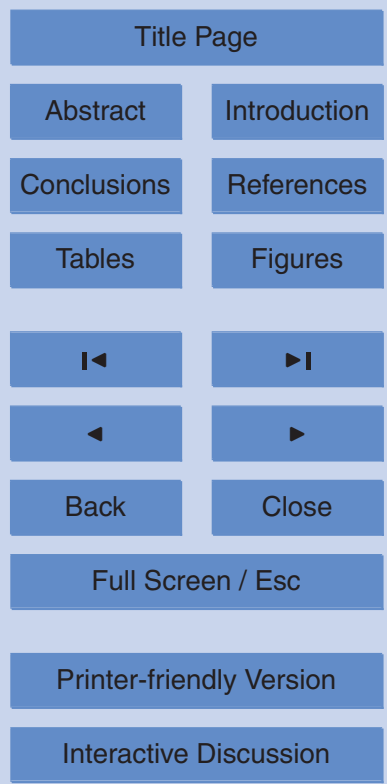


the point of investigations of glaciers and ocean interaction and of sea level changes due to sea ice calving rate changes.

The description of ice shelf flexures and vibrations were developed in (Holdsworth, and Glynn, 1978; Goodman et al., 1980; Wadhams, 1986; Turcotte and Schubert, 5 2002) using the thin plate approximation. These models allow calculations of ice shelf deflections and bending stresses generated by vibration processes, and the assessment of possible effects of tides and ocean swells on calving processes. Further developments of elastic-beam models for description of ice shelf flexures consist in applications of visco-elastic rheological models. In particular, tidal flexure of ice shelf was 10 obtained by linear visco-elastic Burgers model in Reeh et al. (2003).

Ice-stream response to ocean tides was described by full Stokes 2-D finite-element employing a non-linear visco-elastic Maxwell rheological model by Gudmundsson (2011). This modeling work revealed that tidally induced ice-stream motion is strongly sensitive to the parameters of the sliding law. In particular, a non-linear sliding law al15 lows the explanation of ice stream response to ocean forcing at long-tidal periods (MSf) through a non-linear interaction between the main semi-diurnal tidal components (Gudmundsson, 2011).

A 2-D finite-element flow-line model with an elastic rheology was developed by O. V. Sergienko in Bromirski et al. (2010) and used to estimate mechanical impact of high-freq tidal action on stress regime of ice shelves. In this model ocean water was considered as incompressible, inviscid fluid and is described by a velocity potential.

Here ice shelf flexures modeling is performed by 2-D finite-difference elastic model. Sub-ice-shelf sea water flow is described by the wave equation for the sub-ice-shelf pressure perturbations (Holdsworth and Glynn, 1978). The main aim of this work is to derive equations and corresponding boundary conditions describing the impact of tidal action on ice shelves, and to present a finite-difference model of the vibrating motion within the glacier, ice shelf and sub-ice-shelf sea system. In the model ice shelf flexures/vibrations are considered as a response to incoming pressure perturbations. The pressure perturbations are in turn caused by changes in sea level. Ice shelf

\section{Ice shelf flexures modeled with a 2-D elastic flow line model}

Y. V. Konovalov

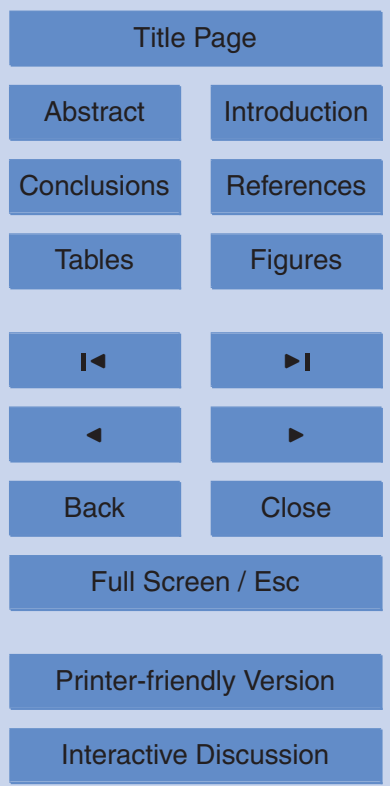


flexures were obtained by the model for a wide spectrum of the pressure perturbations frequencies.

\section{Field equations}

\subsection{The 2-D finite-difference elastic model}

5 The 2-D model is based on well-known 2-D momentum equations that can be applied to a vertical cross-section along a flow line (Lamb, 1994; Landau and Lifshitz, 1986; Lurie, 1999; Hutter and Jöhnk, 2004):

$$
\left\{\begin{array}{l}
\frac{\partial \sigma_{\mathrm{xx}}}{\partial x}+\frac{\partial \sigma_{\mathrm{xz}}}{\partial z}=\rho \frac{\partial^{2} U}{\partial t^{2}} \\
\frac{\partial \sigma_{\mathrm{zx}}}{\partial x}+\frac{\partial \sigma_{\mathrm{zz}}}{\partial z}=\rho g+\rho \frac{\partial^{2} W}{\partial t^{2}} .
\end{array}\right.
$$

Finite-difference method suggests the coordinate transformation $x, z \rightarrow x, \xi$, which

transfigures a cross-section into the rectangle $\Pi=\{0 \leq x \leq L ; 0 \leq \xi \leq 1\}$ (Pattyn, 2000, 2002). After the coordinate transformation the boundary conditions for the system of momentum Eq. (1) at the upper glacier surface (free surface) can be written as

$$
\left\{\begin{array}{l}
\left(\frac{\partial \sigma_{\mathrm{xx}}}{\partial x}\right)^{1}+\left(\xi_{\mathrm{x}}^{\prime} \frac{\partial \sigma_{\mathrm{xx}}}{\partial \xi}\right)^{1}+\frac{1}{H} \frac{d h_{\mathrm{s}}}{d x} \frac{1}{\Delta \xi} \sigma_{\mathrm{xx}}^{1}-\frac{1}{H} \frac{1}{\Delta \xi} \sigma_{\mathrm{xz}}^{2}=\rho \frac{\partial^{2} U_{\mathrm{s}}}{\partial t^{2}} \\
\left(\frac{\partial \sigma_{\mathrm{xz}}}{\partial x}\right)^{1}+\left(\xi_{\mathrm{x}}^{\prime} \frac{\partial \sigma_{\mathrm{xz}}}{\partial \xi}\right)^{1}+\frac{1}{H} \frac{d h_{\mathrm{s}}}{d x} \frac{1}{\Delta \xi} \sigma_{\mathrm{xz}}^{1}-\frac{1}{H} \frac{1}{\Delta \xi} \sigma_{\mathrm{zz}}^{2}=\rho g+\rho \frac{\partial^{2} W_{\mathrm{s}}}{\partial t^{2}}
\end{array}\right.
$$

where the index "1" indicates that corresponding terms are approximated in grid nodes located at ice surface and the index " 2 " corresponds to next sub-ice-surface grid layer.

\section{Ice shelf flexures modeled with a 2-D elastic flow line model}

Y. V. Konovalov

Title Page

Abstract Introduction

Conclusions References

Tables Figures

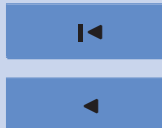

- I

Back

Close

Full Screen / Esc

Printer-friendly Version

Interactive Discussion 
Boundary conditions at shelf base differ from Eq. (2) due to sea water pressure forcing at the shelf base and are given by

$$
\left\{\begin{array}{c}
\left(\frac{\partial \sigma_{\mathrm{xx}}}{\partial x}\right)^{N_{\xi}}+\left(\xi_{\mathrm{x}}^{\prime} \frac{\partial \sigma_{\mathrm{xx}}}{\partial \xi}\right)^{N_{\xi}}-\frac{1}{H} \frac{1}{\Delta \xi} \frac{d h_{\mathrm{b}}}{d x} \sigma_{\mathrm{xx}}^{N_{\xi}}+\frac{1}{H} \frac{1}{\Delta \xi} \sigma_{\mathrm{xz}}^{N_{\xi}-1}= \\
=\frac{1}{\Delta \xi} \frac{d h_{\mathrm{b}}}{d x} \rho g+\frac{1}{H} \frac{1}{\Delta \xi} \frac{d h_{\mathrm{b}}}{d x} P^{\prime}+\rho \frac{\partial^{2} U_{\mathrm{b}}}{\partial t^{2}} ; \\
\left(\frac{\partial \sigma_{\mathrm{xz}}}{\partial x}\right)^{N_{\xi}}+\left(\xi_{\mathrm{x}}^{\prime} \frac{\partial \sigma_{\mathrm{xz}}}{\partial \xi}\right)^{N_{\xi}}-\frac{1}{H} \frac{1}{\Delta \xi} \frac{d h_{\mathrm{b}}}{d x} \sigma_{\mathrm{xz}}^{N_{\xi}}+\frac{1}{H} \frac{1}{\Delta \xi} \sigma_{\mathrm{zz}}^{N_{\xi}-1}= \\
=\rho g-\frac{1}{\Delta \xi} \rho g-\frac{1}{H} \frac{1}{\Delta \xi} P^{\prime}+\rho \frac{\partial^{2} W_{\mathrm{b}}}{\partial t^{2}} .
\end{array}\right.
$$

where index " $N_{\xi}$ " corresponds to grid layer located at ice shelf base, $P^{\prime}$ is the deviation 5 from the hydrostatic pressure in sub-ice-shelf sea water.

Boundary conditions at shelf front after finite differencing in horizontal direction can be written on the following form

$$
\left\{\begin{array}{l}
-\frac{1}{\Delta x_{N_{\mathrm{x}}-1}}\left(\sigma_{\mathrm{xx}}\right)_{N_{\mathrm{x}}-1}+\left(\xi_{\mathrm{x}}^{\prime} \frac{\partial \sigma_{\mathrm{xx}}}{\partial \xi}\right)_{N_{\mathrm{x}}}=-\frac{1}{\Delta x_{N_{\mathrm{x}}-1}} f(\xi)+\rho\left(\frac{\partial^{2} U}{\partial t^{2}}\right)_{N_{\mathrm{x}}} \\
-\frac{1}{\Delta x_{N_{\mathrm{x}}-1}}\left(\sigma_{\mathrm{xz}}\right)_{N_{\mathrm{x}}-1}-\left(\frac{1}{H} \frac{\partial \sigma_{\mathrm{zz}}}{\partial \xi}\right)_{N_{\mathrm{x}}}=\rho g+\rho\left(\frac{\partial^{2} W}{\partial t^{2}}\right)_{N_{\mathrm{x}}} ;
\end{array}\right.
$$

where $f(\xi)=\left\{\begin{array}{l}0, \xi<h_{\mathrm{s}} / H ; \\ \rho_{\mathrm{w}} g\left(h_{\mathrm{s}}-\xi H\right), \xi \geq h_{\mathrm{s}} / H .\end{array}\right.$ and index "N$N_{\mathrm{x}}$ " corresponds to grid layer located at ice shelf front.

Taking into account basal sliding, the boundary conditions at glacier base for linear friction law are

$$
\left\{\begin{array}{l}
-\frac{d h_{\mathrm{b}}}{d x}\left(\sigma_{\mathrm{xx}}-\sigma_{\mathrm{zz}}\right)+\sigma_{\mathrm{xz}}\left[1-\left(\frac{d h_{\mathrm{b}}}{d x}\right)^{2}\right]=K_{\mathrm{fr}}\left(u_{\mathrm{b}}+w_{\mathrm{b}} \frac{d h_{\mathrm{b}}}{d x}\right) \sqrt{1+\left(\frac{d h_{\mathrm{b}}}{d x}\right)^{2}} \\
-\frac{d h_{\mathrm{b}}}{d x} U_{\mathrm{b}}+W_{\mathrm{b}}=0
\end{array}\right.
$$

where $u_{\mathrm{b}}, w_{\mathrm{b}}$ are the mean horizontal and vertical ice flow velocity components that can be derived by ice flow models and then substituted into Eq. (5), and $K_{\mathrm{fr}}$ is a friction coefficient.

\section{Ice shelf flexures modeled with a 2-D elastic flow line model}

Y. V. Konovalov

Title Page

Abstract Introduction

Conclusions

Tables

References

Figures

14

$\triangleleft$

Back

Close

Printer-friendly Version

Interactive Discussion 
Constitutive relationships between stress tensor components and displacements correspond to Hook's law (Landau and Lifshitz, 1986):

$$
\left\{\begin{array}{l}
\sigma_{\mathrm{xx}}=\frac{E}{(1+v)(1-2 v)}\left\{(1-v)\left(\frac{\partial U}{\partial x}+\xi_{\mathrm{x}}^{\prime} \frac{\partial U}{\partial \xi}\right)-v \frac{1}{H} \frac{\partial W}{\partial \xi}\right\} ; \\
\sigma_{\mathrm{zz}}=\frac{E}{(1+v)(1-2 v)}\left\{-(1-v) \frac{1}{H} \frac{\partial W}{\partial \xi}+v\left(\frac{\partial U}{\partial x}+\xi_{\mathrm{x}}^{\prime} \frac{\partial U}{\partial \xi}\right)\right\} \\
\sigma_{\mathrm{xz}}=\frac{E}{2(1+v)}\left\{-\frac{1}{H} \frac{\partial U}{\partial \xi}+\frac{\partial W}{\partial x}+\xi_{\mathrm{x}}^{\prime} \frac{\partial W}{\partial \xi}\right\} .
\end{array}\right.
$$

Substitution of these relationships into Eqs. (1)-(5) gives final equations of the model.

\subsection{Sub-ice-shelf pressure perturbations}

Sub-ice-shelf sea water flow produces variation in pressure $\left(P^{\prime}\right)$, and gives rise to deviations from the hydrostatic pressure. The pressure perturbations are described by the wave equation (Holdsworth and Glynn, 1978):

$\frac{\partial^{2} W_{\mathrm{b}}}{\partial t^{2}}=\frac{1}{\rho_{\mathrm{w}}} \frac{\partial}{\partial x}\left(d_{0}(x) \frac{\partial P^{\prime}}{\partial x}\right)$

10 where $d_{0}(x)$ is the depth of the sub-ice-shelf channel, $W_{\mathrm{b}}(x, t)$ is the ice shelf base vertical deflection.

\section{Numerical experiments}

The numerical experiments with ice shelf flexures were carried out for harmonic incoming pressure perturbations $P^{\prime}$ and applied to a flow line down one of the four fast flowing ice streams of the Academy of Sciences Ice Cap (Dowdeswell et al., 2002) (Fig. 1). The $C-C^{\prime}$ profile (Dowdeswell et al., 2002) was continued out onto the ice shelf using an idealized trapezoidal geometry (Holdsworth and Glynn, 1978). The ice shelf length, together with sub-ice-shelf channel depth distribution $d_{0}(x)$, are considered as the model's parameters (Fig. 1).

\section{Ice shelf flexures modeled with a 2-D elastic flow line model}

Y. V. Konovalov

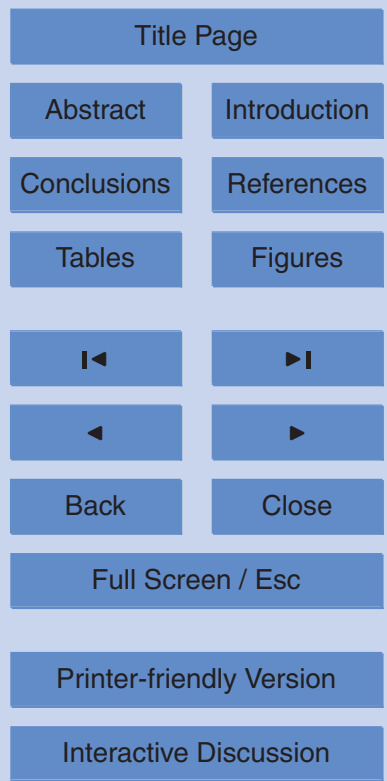


It is assumed that incident ocean waves induce cyclical pressure perturbations at the ice shelf front. Thus, the boundary condition for Eq. (7) can be formulated for pressure perturbations

$P^{\prime}(L, t)=\rho_{\mathrm{w}} g A \sin \omega t$,

5 where $\omega$ and $A$ are the frequency and the amplitude of the incident ocean wave, respectively.

\subsection{Tidal waves}

Ice shelf response to the incoming pressure perturbations depends on ice shelf length $\left(L_{\text {sh }}\right)$. For a given ice shelf thickness distribution, Young's modulus and Poisson's ra10 tio, the vertical amplitude of ice shelf terminus increases with ice shelf length (see Fig. 2a, b). On the other hand, for a given ice shelf thickness and length, the vertical amplitude increases with decreasing Young's modulus (see Fig. 3). For a given set of rheological parameters, an ice shelf length can be found for which the modeled ice shelf vertical deflections equals that of the amplitude of incident ocean wave. In particular, the maximum of the amplitude of vertical deflections corresponds (approximately equals) to the amplitude of incident ocean wave (Fig. 3) at the sets of the parameters: (i) $E=9 \mathrm{GPa}, v=0.33$ (Schulson, 1999) and $L_{\mathrm{sh}} \approx 2 \mathrm{~km}$; (ii) $E=1 \mathrm{GPa}, v=0.45$ (Gudmundsson, 2011) and $L_{\text {sh }} \approx 1.2 \mathrm{~km}$.

Linear dependences of the $d_{0}$ on the distance $x$ in Eq. (7) were considered in the 20 model, i.e. the $d_{0}$ linearly increases from a value $d_{1}$ at the grounding line to a value $d_{2}$ at the ice front, that is $d_{0}(x)=d_{1}+\left(\Delta d / L_{\text {sh }}\right)\left(x-L_{\text {gl }}\right)$.

Increase of the coefficient of the linear distribution $\left(\Delta d / L_{\text {sh }}\right)$ leads to enhancement of the ice shelf deflection maximum (Fig. 4). More precisely, 5-times growing of the coefficient $\left(\Delta d / L_{\text {sh }}\right)$ reveals about $20 \%$ rise in the amplitude of the ice shelf deflections.

In addition to the linear distributions the sinusoidal distribution of the $d_{0}$ was considered, that is $d_{0}(x)=d_{1}+\left(\Delta d / L_{\text {sh }}\right)\left(x-L_{\text {gl }}\right)+d_{3}\left(-1+\cos \left(2 \pi\left(x-L_{\text {gl }}\right) / L_{\text {sh }}\right)\right)$. Practically, this distribution defines the bump located at the sea bottom in the middle of the 2847

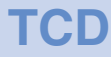

$5,2841-2863,2011$

\section{Ice shelf flexures modeled with a 2-D elastic flow line model}

Y. V. Konovalov

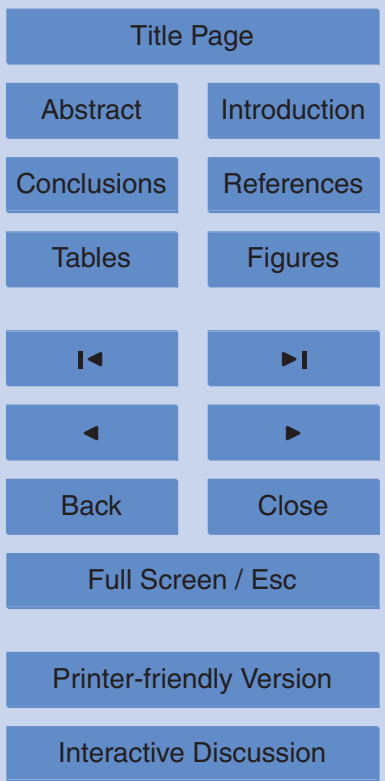


sub-ice-shelf cannel (Fig. 1). The bumpy perturbed sea bottom also leads to increase of the ice shelf deflection maximum (curve 6 in Fig. 4).

The ice shelf response to the tidal wave with semi-diurnal frequency and modulated by MSf frequency (Gudmundsson, 2011) is represented in Fig. 5 and is in concordance 5 with observed ice shelf histories (Basis et al., 2008). The asymmetric response of the ice shelf, that is revealed in excess of the amplitude of upward ice shelf terminus deflection (Fig. 5), depends on geometry of the ice shelf, incoming wave amplitude and mechanical properties of ice. In particular, the effect grows with the incoming wave amplitude increase at a given trapezoidal geometry, which supposes ice shelf

10 thinning, and mechanical properties of ice; or the effect grows, for example, when Young's modulus decreases.

\subsection{Infragravity waves (response to high-frequency forcing)}

Responses of the ice shelf to the harmonic incoming waves with high frequencies ranging from 0.004 to $0.02 \mathrm{~Hz}$, differs in a number of ways from the response at typical tidal 15 frequencies of hours and days (Fig. 6). The main difference is that the amplitude of the ice shelf vertical deflections depends on the frequency of the forcing, i.e. the amplitude of the incident wave is considered as a given value, for example, is equal to $0.3 \mathrm{~m}$ (Bromirski et al., 2010), for all frequencies in the experiment (Fig. 6), but the amplitude of the ice shelf terminus vertical deflections ranging from about $0.05 \mathrm{~m}$ (for $0.02 \mathrm{~Hz}$ ) to 20 about $1.5 \mathrm{~m}$ (for $0.0057 \mathrm{~Hz}$ ).

In other words, the amplitude spectral distribution appears in the infragravity part of the ocean waves spectrum (Fig. 7). For a wide spectrum of ocean waves, which begins from tidal frequencies and extends till the lower boundary of infragravity part of the spectrum, i.e. it's supposed that theoretically the spectrum is continuous, the ice shelf deflections follow to the incoming waves. "Follow" means that the amplitude of ice shelf terminus deflections corresponds (approximately equals) to the amplitude of the incoming wave (Fig. 7). In the infragravity part of the spectrum the amplitude of the ice shelf deflections achieves the maximum at $T \approx 165 \mathrm{~s}$, where the amplitude of

\section{Ice shelf flexures modeled with a 2-D elastic flow line model}

Y. V. Konovalov

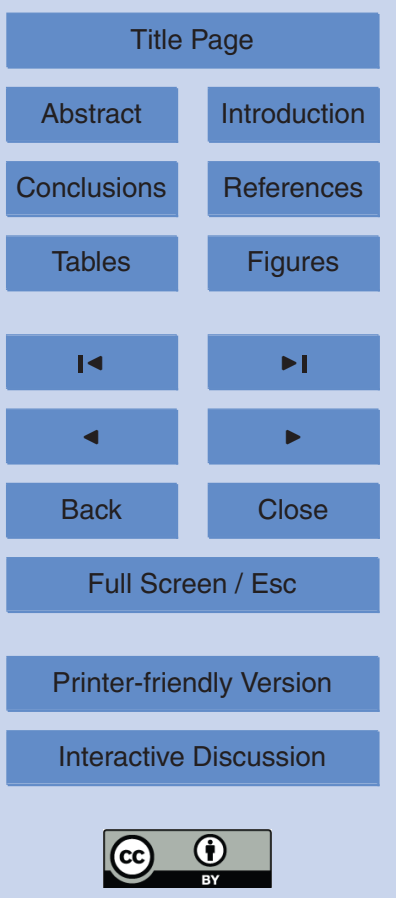


the terminus deflections is approximately equal to $5 A$, and $A$ is the amplitude of the incoming wave.

\section{Discussion}

Modeled ice shelf response to incoming pressure perturbation depends on a set of 5 model's parameters, i.e. the amplitudes of ice shelf vertical deflections are in general not equal to the amplitude $(A)$ of incident ocean wave. At the point of the mathematical statement of the problem there are no contradictions in these results because, despite the sub-ice-shelf water being incompressible fluid, the incoming (into sub-iceshelf channel) sea water flow is unlimited in the model. For other model parameters kept fixed, an ice shelf length can be found for which calculated amplitudes of ice shelf deflections equal that of the incoming wave.

A peak in ice shelf amplitudes is obtained by the model for $L_{\mathrm{gl}}+L_{\text {sh }} / 2<x<L_{\mathrm{gl}}+L_{\mathrm{sh}}$ (Fig. 4), with the maximum of vertical deflection at $x \approx L_{\mathrm{gl}}+0.85 L_{\mathrm{sh}}$. Apparently, this existence of the maxima is related to the hydrostatic pressure forcing at the glacier 15 terminus. On the other hand, the possibility cannot be ruled out that this is due to some numerical effects. Performing a range of numerical experiments showed that the ice shelf vertical deflections distributions are sensitive to the boundary conditions approximations, especially, at ice shelf front and at ice shelf base and are furthermore also sensitive to the forms of basic equations. For example, the changing the second equation from Eq. (3) to the mathematically equal equation, which is rewritten on the integral form:

$\frac{\partial}{\partial x} \int_{0}^{1} H \sigma_{x z} d \xi+P^{\prime}=0$,

leads to the appropriate flexures with "concavities" (Fig. 8b) versus the flexures with "protuberances" (Fig. 8a) obtained in the basic model. Thus, the numerical experiments

\section{Ice shelf flexures modeled with a 2-D elastic flow line model}

Y. V. Konovalov

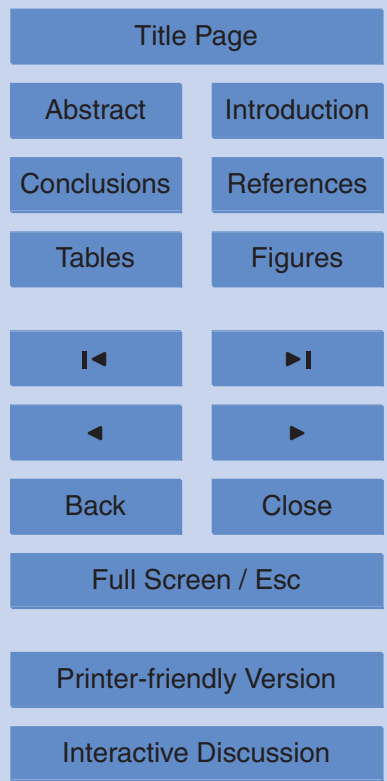


with different forms of the boundary conditions proves that the protuberances in ice shelf flexures obtained by the model developed in this manuscript are a numerical effects. Moreover, at the mathematical point the numerical solutions in different models, that differ in forms of the equations, converge to a different limits and this thing means 5 that the problem is ill-posed (for the full models). Besides, the numerical solution obtained by the model with Eq. (9) becomes unstable in the high-freq part of the spectrum. Nevertheless, the developed model based on Eq. (1)-(7) allows to obtain realistic results that, generally, in accordance with observations and known models (Turcotte and Schubert, 2002) (Fig. 9).

10 Further, relatively small spread in the values of the ice shelf deflections amplitudes (about $30 \%$ deviation in the ice shelf deflections amplitudes), that is induced by variations in sub-ice-shelf channel depth distribution (Fig. 4), supports the application of the models based on the elastic flexural wave equation (Goodman et al., 1980; Wadhams, 1986; Turcotte and Schubert, 2002), which doesn't take into account the sub-ice-shelf channel depth distribution. The small spread in the deflections is a consequence of general assumptions of the model, i.e. Eq. (7) is valid if sub-ice-channel depth changes slowly (Holdsworth and Glynn, 1978) ("slowly" means the depth changes satisfy to $\Delta d / d \ll 1$ at $\Delta x \approx d)$. In general case the hydrodynamic equations are required and apparently the response will be more sensitive to sub-ice-channel depth variations.

Amplitude of the ice shelf terminus displacements corresponds and approximately equals $\left(\approx 0.8 A\right.$ for ice shelf length $L_{\text {sh }}=2 \mathrm{~km}$, Young's modulus $E=9 \mathrm{GPa}$ and Poisson's ratio $v=0.33$ ) to the amplitude of incident ocean wave for a wide part of the spectrum, which begins from tidal frequencies and extends to the lower boundary of infragravity frequencies. In fact, spectral distribution of the amplitude of ice shelf vertical displacements appears in the infragravity part of the incident waves spectrum. In particular, the amplitude of the ice shelf terminus displacements increases, achieves the maximum at $T \approx 165 \mathrm{~s}$ and then decreases, so the basal pressure perturbations at high frequencies (ocean swells) insignificantly affect to the ice shelf deflections in comparison with infragravity and tidal waves (except the ability of resonance effects at

\section{Ice shelf flexures modeled with a 2-D elastic flow line model}

Y. V. Konovalov

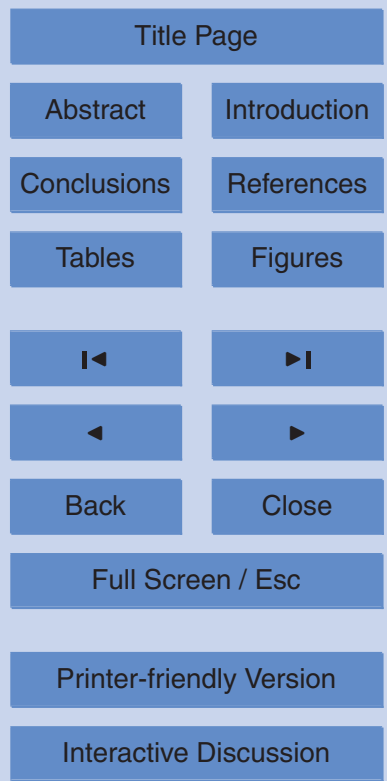


ocean swells frequencies). Thus, the amplitude spectral distribution obtained by the model is in accordance with the results represented in Bromirski et al. (2010): the rms amplitude of IG wave are about a factor 3 greater than swell, when sea ice is absent. The impact of ocean swells to ice shelf front transforms to surface Rayleigh's waves 5 and the response exponentially decreases with the ice depth (Goodman et al., 1980; Wadhams, 1986).

The shape of the maximum in the amplitude spectral distribution (Fig. 7) implies resonance origin of the maximum. The eigenvalue problem can be solved numerically in the following way. The harmonic forced vibrations are considered and the 10 resonance peaks define the eigenfrequencies of the system. The harmonic forced vibrations problem implies that the harmonic solutions of the Eq. (1)-(5), (7) are defined, i.e. $\frac{\partial^{2} U_{i}(x, t)}{\partial t^{2}}$ are replaced with $-\omega^{2} \tilde{U}_{i}(x)$ and $\rho g$ in Eq. (1)-(4) represents the amplitude of the harmonic force per a unit volume - more precisely, all loadings in Eq. (1)-(5) represent the amplitudes of harmonic forces per a unit volume or per a unit square of boundary. The solutions of the harmonic forced vibrations problem confirm the suggestion (about the resonance origin of the maximum) and gives for the eigenfrequencies the values $\omega_{1} \approx 0.0061 \mathrm{~Hz}\left(T_{1} \approx 164 \mathrm{~s}\right) ; \omega_{2} \approx 0.027 \mathrm{~Hz}\left(T_{2} \approx 36.7 \mathrm{~s}\right)$; $\omega_{3} \approx 0.035 \mathrm{~Hz}\left(T_{3} \approx 28.7 \mathrm{~s}\right) ; \omega_{4} \approx 0.065 \mathrm{~Hz}\left(T_{4} \approx 15.4 \mathrm{~s}\right) ; \omega_{5} \approx 0.106 \mathrm{~Hz}\left(T_{5} \approx 9.4 \mathrm{~s}\right) ;$ $\omega_{6} \approx 0.11 \mathrm{~Hz}\left(T_{6} \approx 9.08 \mathrm{~s}\right)$ (Fig. 10). It should be underlined that the set of the six 20 eigenfrequencies represents the eigenfrequencies of the "full" system, which includes the glacier, the ice shelf and the sub-ice-shelf water. At the point of research of the ice shelf and incident ocean wave interaction only three modes from the set are essential: $\omega_{1}, \omega_{3}, \omega_{5}$. This conclusion is confirmed by the solutions of the harmonic forced vibrations problem, when only one non-zero loading is applied to the open side of the sub-ice-shelf channel. Hence, the first eigenfrequency appertains to infragravity part of the spectrum, and the maximum of the amplitude of the ice shelf deflections in the infragravity spectrum can be directly associated with the resonance effect.

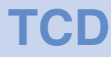

5, 2841-2863, 2011

\section{Ice shelf flexures modeled with a 2-D elastic flow line model}

Y. V. Konovalov

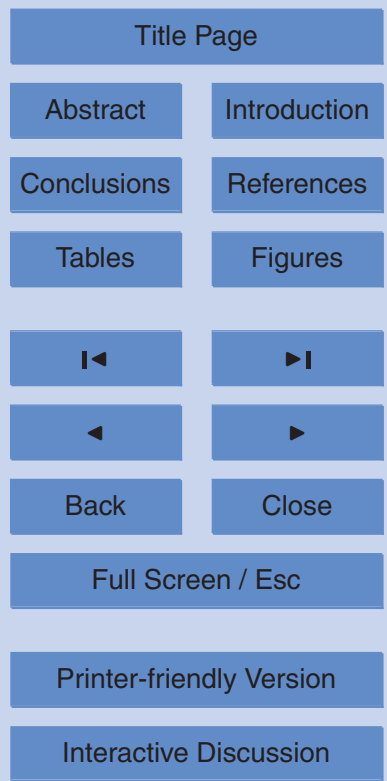




\section{Notation}

A amplitude of incident ocean wave, $\mathrm{m}$

$d_{0} \quad$ depth of the sub-ice-shelf channel, $\mathrm{m}$

E Young's modulus

$g \quad$ gravitational acceleration, $9.8 \mathrm{~m} \mathrm{~s}^{-2}$

$H \quad$ ice thickness, $\mathrm{m}$

$h_{\mathrm{s}} \quad$ ice surface elevation, $\mathrm{m}$

$h_{\mathrm{b}} \quad$ ice bed elevation, $\mathrm{m}$

$L ; L_{g l} ; L_{\text {sh }}$ full ice vertical cross-section length; glacier length; ice shelf length, $m$

$T \quad$ period of incident ocean wave/period of ice shelf vibrations, $\mathrm{s}$

$U \quad$ horizontal deflection of ice, $\mathrm{m}$

$W \quad$ vertical deflection of ice, $m$

$x \quad$ horizontal axis along a flow line, $\mathrm{m}$

$z \quad$ vertical axis pointing upward ( $z=0$ at sea level), $\mathrm{m}$

$\checkmark \quad$ Poisson's ratio

$\rho ; \rho_{\mathrm{w}} \quad$ ice density, $900 \mathrm{~kg} \mathrm{~m}^{-3}$; sea water density, $1030 \mathrm{~kg} \mathrm{~m}^{-3}$

$\sigma_{i k} \quad$ stress tensor components, $\mathrm{Pa}$

$\omega$ frequency of incident ocean wave/frequency of ice shelf vibrations, $\mathrm{Hz}$

Acknowledgements. Author is grateful to the Ministry of Education and Science of Russia (project no. P795). Author is grateful to G. Hilmar Gudmundsson for helpful comments to the 5 manuscript.

\section{References}

Bassis, J. N., Fricker, H. A., Coleman, R., and Minster, J.-B.: An investigation into the forces that drive ice-shelf rift propagation on the Amery Ice Shelf, East Antarcyica, J. Glaciol., 54, 17-27, 2008.

10 Dowdeswell, J. A., Bassford, R. P., Gorman, M. R., Williams, M., Glazovsky, A. F., Macheret, Y. Y., Shepherd, A. P., Vasilenko, Y. V., Savatyuguin, L. M., Hubberten, H.-W., and Miller, H.:

\section{Ice shelf flexures modeled with a 2-D elastic flow line model}

Y. V. Konovalov

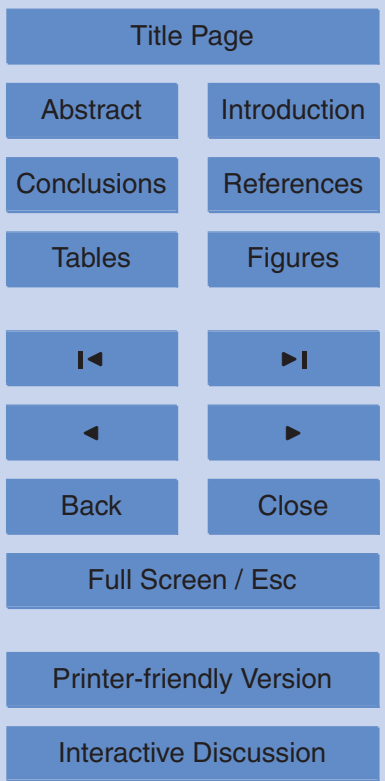


Form and flow of the Academy of Sciences Ice Cap, Severnaya Zemlya, Russian High Arctic, J. Geophys. Res., 107, B4, doi:10.1029/2000JB000129, 2002.

Goodman, D. J., Wadhams, P., and Squire, V. A.: The flexural response of a tabular ice island to ocean swell, Ann. Glaciol., 1, 23-27, 1980.

5 Gudmundsson, G. H.: Ice-stream response to ocean tides and the form of the basal sliding law, The Cryosphere, 5, 259-270, doi:10.5194/tc-5-259-2011, 2011.

Holdsworth, G. and Glynn, J.: Iceberg calving from floating glaciers by a vibrating mechanism, Nature, 274, 464-466, 1978.

Hutter, K. and Jöhnk, K.: Continuum Methods of Physical Modeling, Springer, 2004.

10 Lamb, H.: Hydrodynamics, Cambridge University Press, 6th ed., 1994.

Landau, L. D. and Lifshitz, E. M.: Theory of Elasticity, Vol. 7, Butterworth-Heinemann, 3rd ed., 1986.

Lurie, A. I.: Theory of Elasticity, Springer, 1999.

MacAyeal, D. R., Okal, E. A., Aster, R. C., Bassis, J. N., Brunt, K. M., Cathles, L. M., Drucker, 15 R., Fricker, H. A., Kim, Y.-J., Martin, S., Okal, M. H., Sergienko, O. V., Sponsler, M. P., and Thom, J. E.: Transoceanic wave propagation links iceberg calving margins of Antarctica with storms in tropics and Northern Hemisphere, Geophys. Res. Lett., 33, L17502, doi:10.1029/2006GL027235, 2006.

Meylan, M., Squire, V. A., and Fox, C.: Towards realism in modelling ocean wave behavior in marginal ice zones, J. Geophys. Res., 102, 22981-22991, 1997.

Pattyn, F.: Ice-sheet modeling at different spatial resolutions: focus on the grounding zone, Ann. Glaciol., 31, 211-216, 2000.

Pattyn, F.: Transient glacier response with a higher-order numerical ice-flow model, J. Glaciol., 48, 467-477, 2002.

Reeh, N., Christensen, E. L., Mayer, C., and Olesen, O. B.: Tidal bending of glaciers: a linear viscoelastic approach, Ann. Glaciol., 37, 83-89, 2003.

Schulson, E. M.: The Structure and Mechanical Behavior of Ice, JOM, 51, 21-27, 1999.

Squire, V. A., Dugan, J. P., Wadhams, P., Rottier, P. J., and Liu, A. K.: Of ocean waves and sea ice, Annu. Rev. Fluid Mech., 27, 115-168, 1995.

30 Turcotte, D. L. and Schubert, G.: Geodynamics. Second edition, Cambridge, etc., Cambridge University Press, 2002.

Wadhams, P.: The seasonal ice zone, in: Geophysics of sea ice, edited by: Untersteiner, N., London, etc., Plenum Press, 825-991, 1986.

\section{Ice shelf flexures modeled with a 2-D elastic flow line model}

Y. V. Konovalov

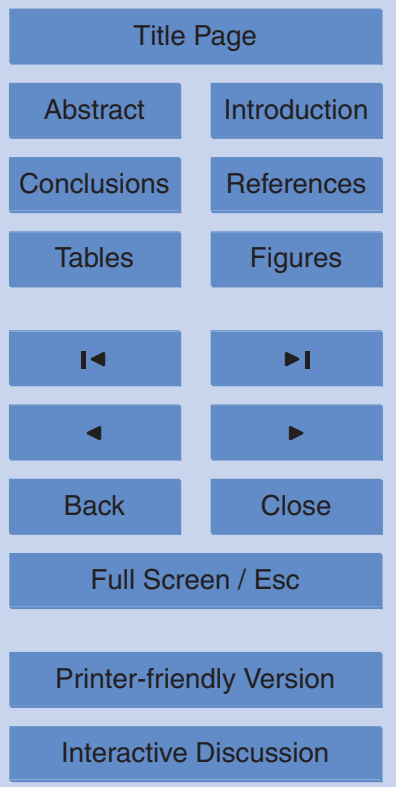




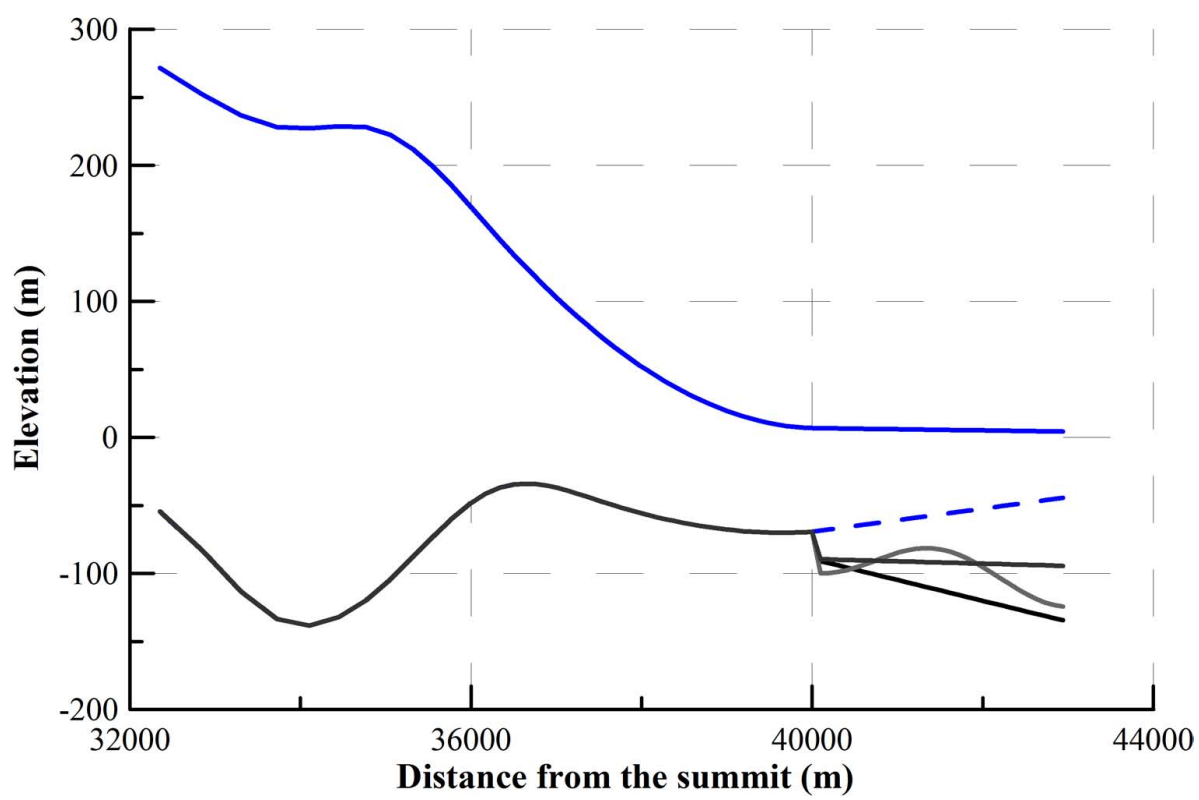

Fig. 1. The part of the $C-C^{\prime}$ profile which crosses down the fast flowing ice stream in the Academy of Sciences Ice Cap (Dowdeswell et al., 2002). The $C-C^{\prime}$ profile was continued by the ice shelf with trapezoidal geometry. The linear depth distributions of the sub-ice-shelf sea water channel and the linear depth distribution perturbed by sinusoidal function are considered in the numerical experiments. Ice shelf thickness at the grounding line is about $76.2 \mathrm{~m}$.

\section{Ice shelf flexures modeled with a 2-D elastic flow line model}

Y. V. Konovalov

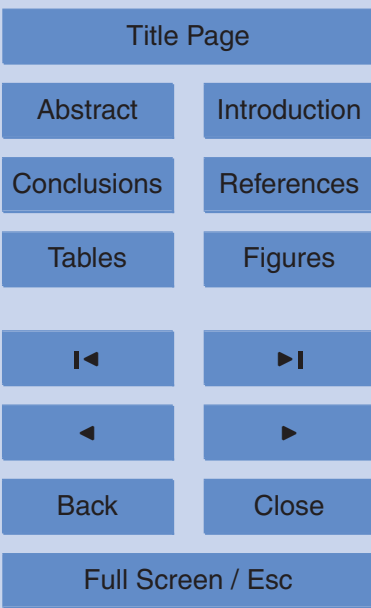

Printer-friendly Version

Interactive Discussion 

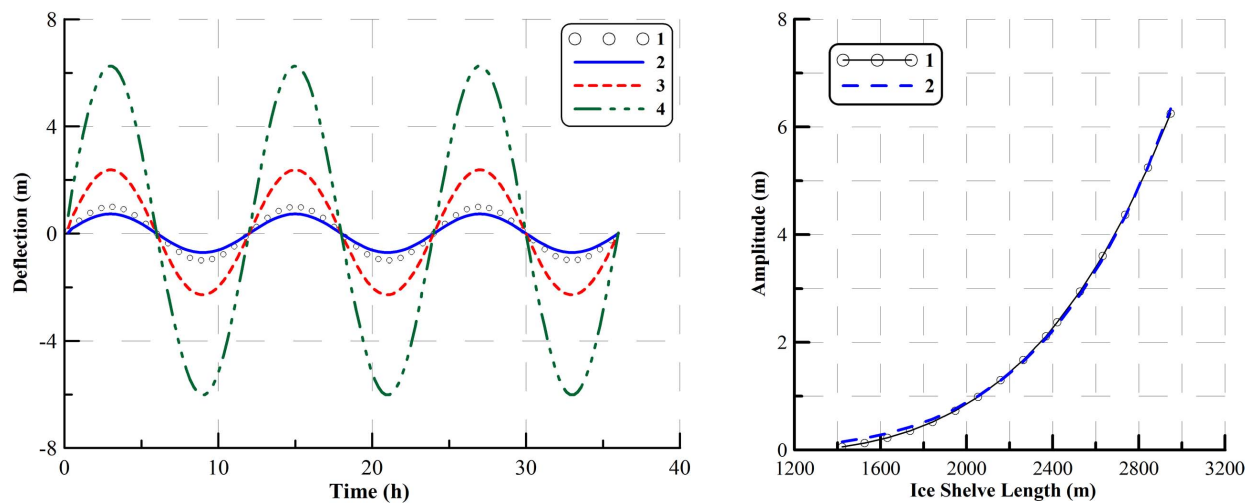

\section{Ice shelf flexures modeled with a 2-D elastic flow line model}

Y. V. Konovalov

Fig. 2. (a) Ice shelf terminus deflection histories obtained by the full elastic model at some values of ice shelf length: 1 - sea level changes at ice shelf terminus (simple sinusoidal history $A \sin \omega t$ ); $2-L_{\mathrm{sh}}=2 \mathrm{~km} ; 3-L_{\mathrm{sh}}=2.5 \mathrm{~km} ; 4-L_{\mathrm{sh}}=3 \mathrm{~km}$. (b) Ice shelf terminus deflection amplitude versus ice shelf length: 1 - the values obtained in the numerical experiments; 2 - the approximation of the calculated values by a simple power function $\tilde{A}\left(L_{\text {sh }}\right)^{n}$, where $\tilde{A} \approx$ $1.28 \times 10^{-17} \mathrm{~m}^{1-n}, n \approx 5.1$. Young's modulus $E=9 \mathrm{GPa}$, Poisson's ratio $v=0.33$, period of the vibrations $T=12 \mathrm{~h}$ (semi- diurnal periodicity), incoming wave amplitude $A=1 \mathrm{~m}$.

Title Page

Abstract Introduction

Conclusions

References

Tables

Figures

14

$>1$

4

Back

Close

Full Screen / Esc

Printer-friendly Version

Interactive Discussion 


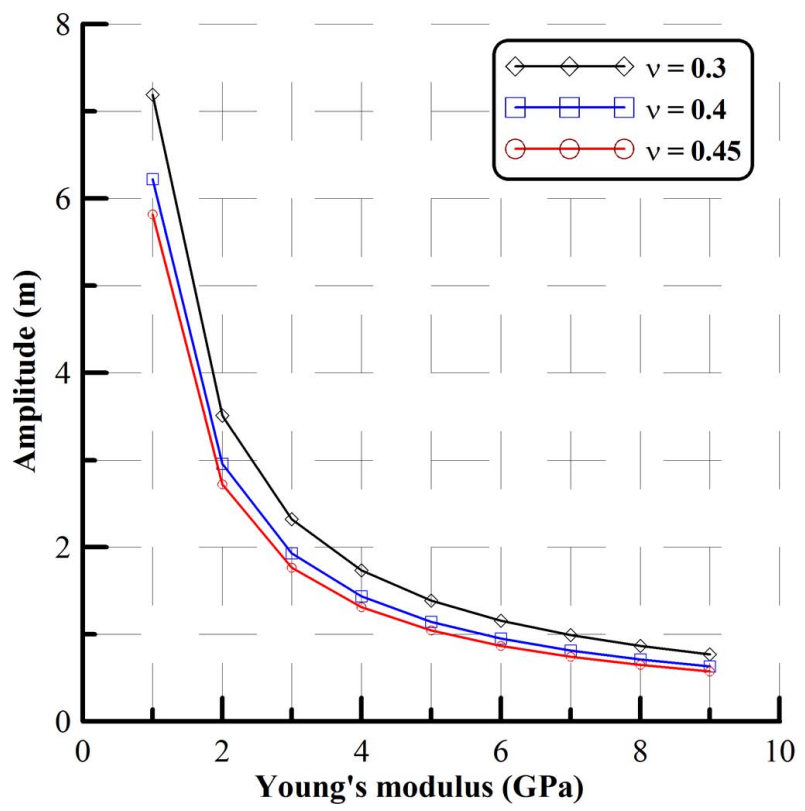

\section{Ice shelf flexures modeled with a 2-D elastic flow line model}

Y. V. Konovalov

Title Page

Abstract

Conclusions

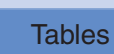

14

4

Back
Introduction

References

Figures

$\rightarrow 1$

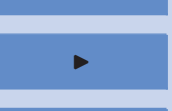

Close

Fig. 3. Ice shelf terminus deflection amplitude versus a value of Young's modulus. The curves differ in a value of Poisson's ratio. Ice shelf length $L_{\mathrm{sh}}=2 \mathrm{~km}$. Period of the vibrations $T=12 \mathrm{~h}$ (semi-diurnal periodicity), incoming wave amplitude $A=1 \mathrm{~m}$.

\section{Full Screen / Esc}

Printer-friendly Version

Interactive Discussion 


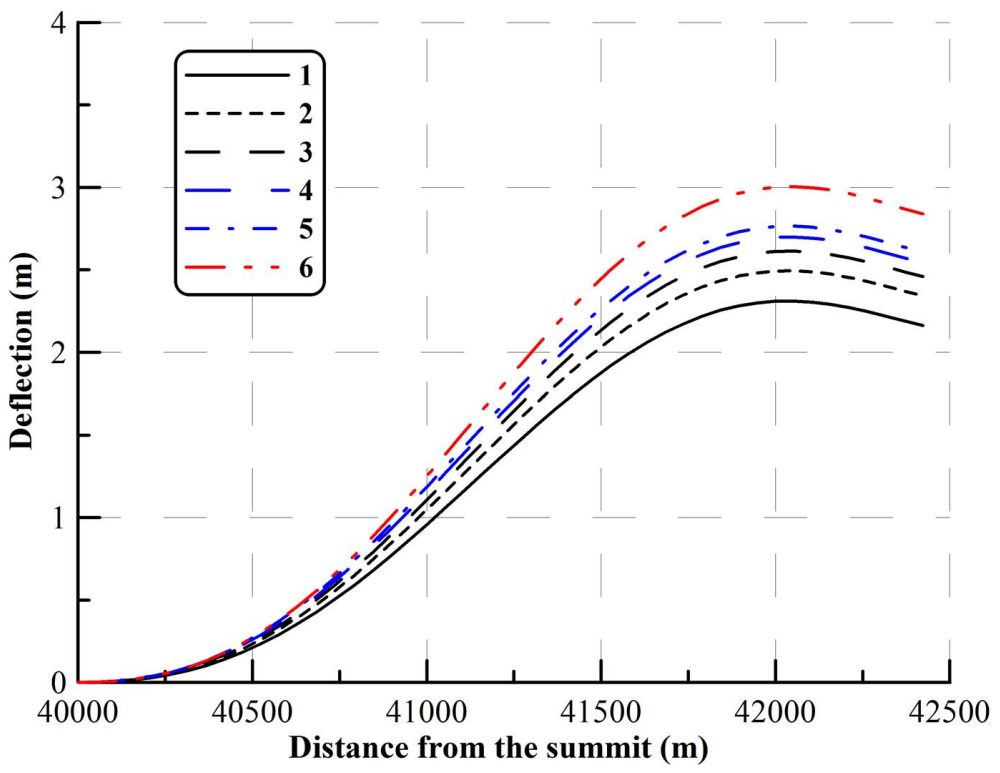

Fig. 4. Ice shelf base deflection distributions obtained by the elastic model at different depth distributions of the sub-ice-shelf channel (Fig. 1). The curves 1-5 have been obtained at the linear depth distributions, i.e. $d_{0}(x)$ linearly changes from $d_{1}=20 \mathrm{~m}$ to a value $d_{2}: 1-d_{2}=20 \mathrm{~m}$; $2-d_{2}=40 \mathrm{~m} ; 3-d_{2}=60 \mathrm{~m} ; 4-d_{2}=80 \mathrm{~m} ; 5-d_{2}=100 \mathrm{~m}$. The curve 6 have been obtained at the sinusoidally perturbed sea bottom (Fig. 1). Young's modulus $E=9 \mathrm{GPa}$, Poisson's ratio $v=0.33$, period of the vibrations $T=12 \mathrm{~h}$ (semi- diurnal periodicity), incoming wave amplitude $A=1 \mathrm{~m}$.

\section{Ice shelf flexures modeled with a 2-D elastic flow line model}

Y. V. Konovalov

\section{Title Page}

\section{Abstract}

Introduction

Conclusions

References

Tables

Figures

14

$\rightarrow$ I

$\triangleleft$

Back

Close

\section{Full Screen / Esc}

Printer-friendly Version

Interactive Discussion 


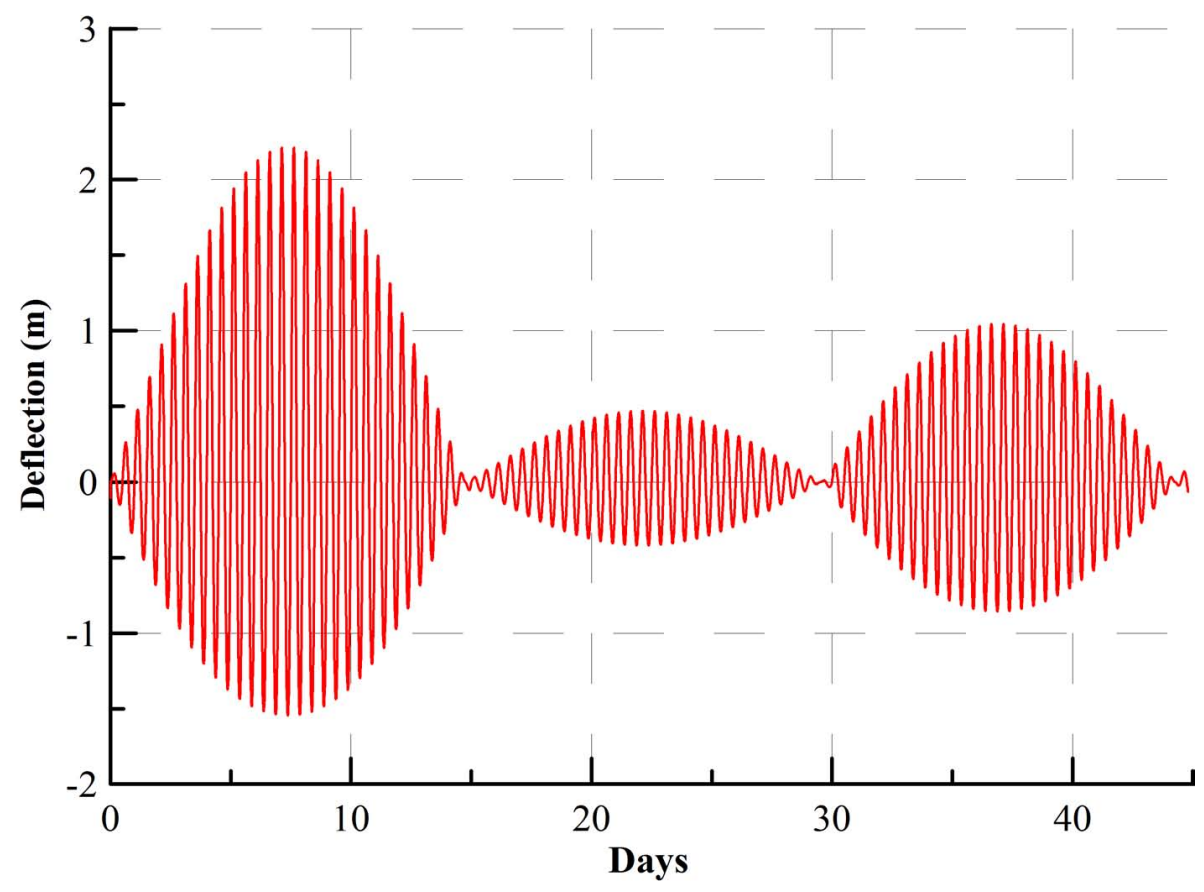

Fig. 5. Ice shelf terminus deflection history obtained at the incident ocean wave with semidiurnal frequency and modulated by MSf frequency (14.76 days) (Gudmundsson, 2011). The time interval covers three periods of the MSf component. The amplitudes of the MSf component are equal to (i) $3 \mathrm{~m}$ at the first period (ii) $0.7 \mathrm{~m}$ at the second period and (iii) $1.5 \mathrm{~m}$ at the third period. Young's modulus $E=9 \mathrm{GPa}$, Poisson's ratio $v=0.33$, ice shelf length $L_{\mathrm{sh}}=2 \mathrm{~km}$.

\section{Ice shelf flexures modeled with a 2-D elastic flow line model}

Y. V. Konovalov

Title Page

Abstract Introduction

Conclusions References

Tables Figures

14 $\rightarrow$

4

Back

Close

\section{Full Screen / Esc}

Printer-friendly Version

Interactive Discussion 


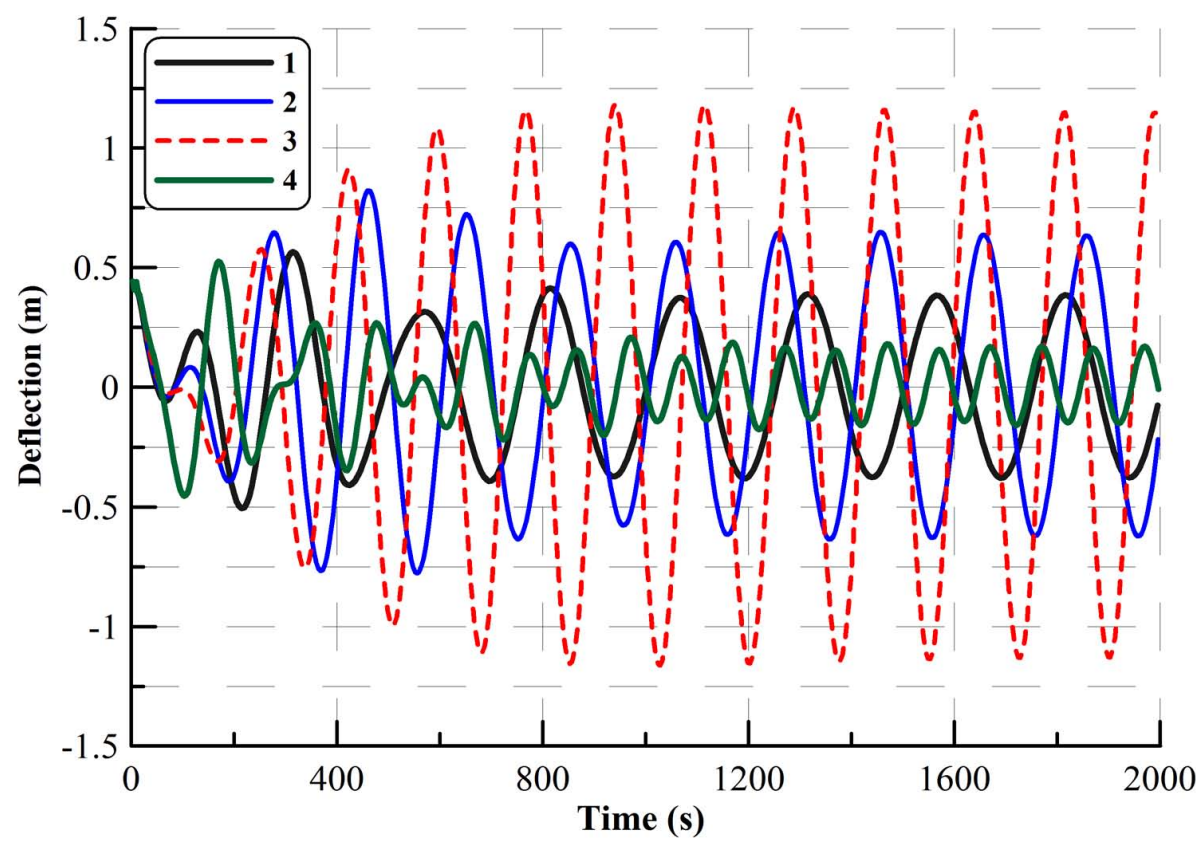

Fig. 6. Ice shelf terminus deflection histories obtained at the infragravity incident ocean waves (Bromirski et al., 2010): $1-T=250 \mathrm{~s} ; 2-T=200 \mathrm{~s} ; 3-T=175 \mathrm{~s} ; 4-T=100 \mathrm{~s}$. Young's modulus $E=9 \mathrm{GPa}$, Poisson's ratio $v=0.33$, incoming wave amplitude $A=0.3 \mathrm{~m}$.

\section{Ice shelf flexures modeled with a 2-D elastic flow line model}

Y. V. Konovalov

Title Page

Abstract

Introduction

Conclusions

References

Tables

Figures

14

$\rightarrow$

4

Back

Close

\section{Full Screen / Esc}

Printer-friendly Version

Interactive Discussion 


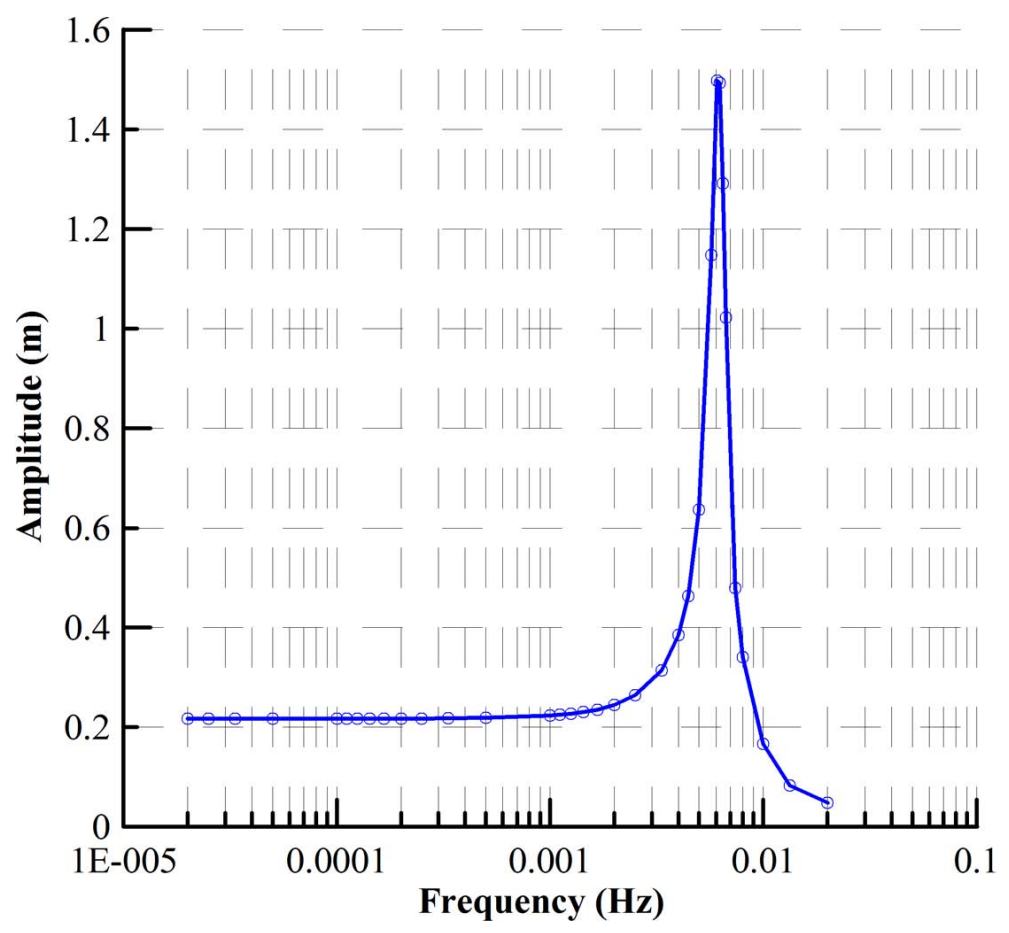

Fig. 7. Ice shelf terminus deflection amplitude versus ocean waves frequency. The boundaries of the considered frequencies range are $5 \times 10^{4} \mathrm{~s}$ and $50 \mathrm{~s}$. The maximum of the amplitude is achieved at $T \approx 165 \mathrm{~s}$. Young's modulus $E=9 \mathrm{GPa}$, Poisson's ratio $v=0.33$, incoming wave amplitude $A=0.3 \mathrm{~m}$.

\section{TCD}

$5,2841-2863,2011$

\section{Ice shelf flexures modeled with a 2-D elastic flow line model}

Y. V. Konovalov

Title Page

Abstract

Introduction

Conclusions

References

Tables

Figures

14

$\rightarrow$

4

Back

Close

\section{Full Screen / Esc}

Printer-friendly Version

Interactive Discussion 

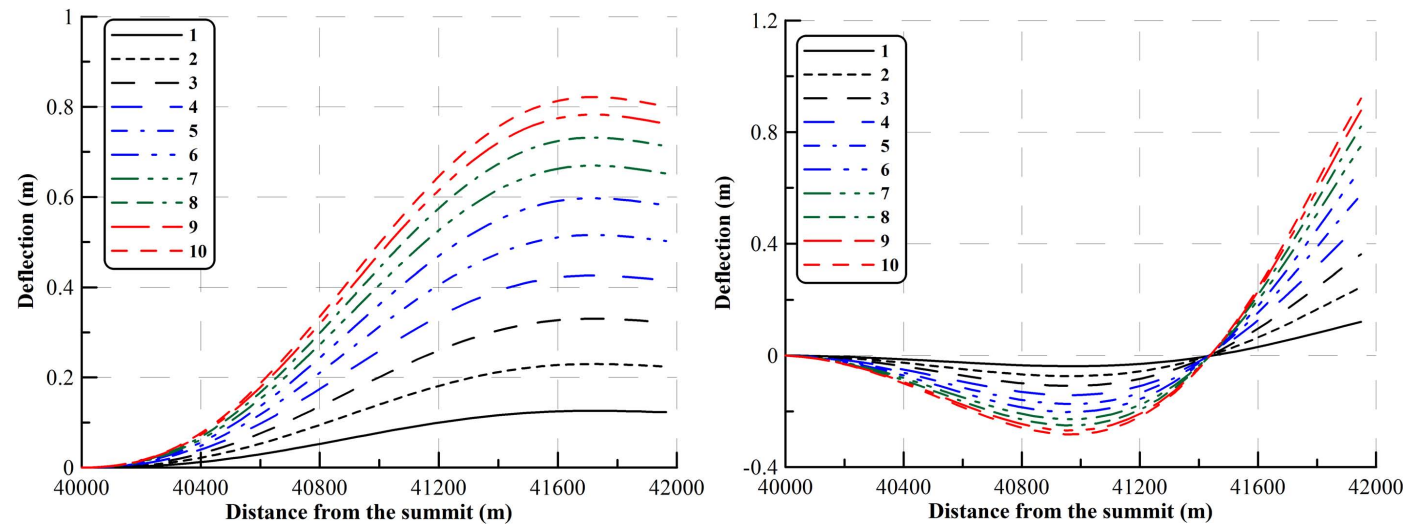

Fig. 8. Successive ice shelf base deflection distributions obtained by (a) the elastic model based on the Eqs. (1)-(5); (b) the elastic model, which differs from the basic model (Eqs. 1-5) in the integral form of the boundary condition - Eq. (9). Two successive curves are separated by the time step $\Delta t=T / 50 . T$ is the period of the vibrations. The time shift between two series (a) and (b) is equal to $T / 2$, i.e. the ice shelf terminus vibrations obtained by model\#2 are in antiphase with respect to incident ocean wave. Young's modulus $E=9 \mathrm{GPa}$, Poisson's ratio $v=0.33$, period of the vibrations $T=12 \mathrm{~h}$ (semi-diurnal periodicity), incoming wave amplitude $A=1 \mathrm{~m}$.

\section{Ice shelf flexures modeled with a 2-D elastic flow line model}

Y. V. Konovalov

\section{Title Page}

\section{Abstract}

Introduction

Conclusions

References

Tables

Figures

14

4

Back

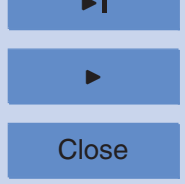

Full Screen / Esc

Printer-friendly Version

Interactive Discussion 


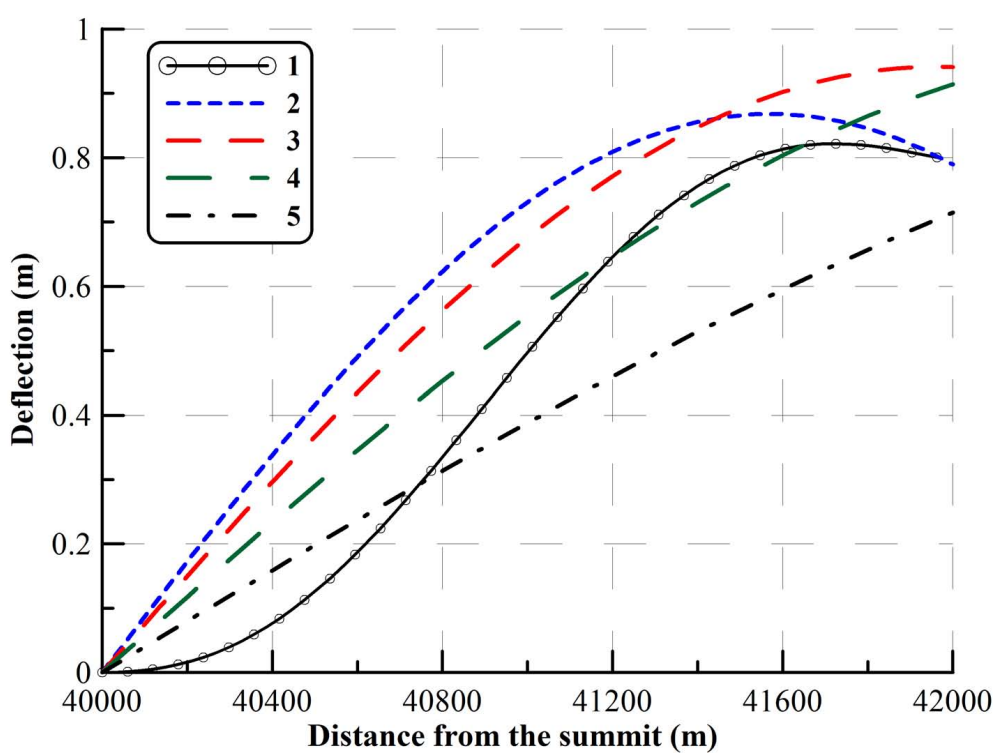

Fig. 9. Ice shelf deflections distributions obtained by (i) the model developed in this manuscript (curve 1) (ii) by the model based on the elastic flexural wave equation (Turcotte and Schubert, 2002) (curves 2-5). In other words, the curves 2-5 are defined by the expression $W(x)=$ $A \sin (k x) /\left(1+(\alpha k)^{4}\right)$, where $\alpha=\left(4 D / \rho_{\mathrm{w}} g\right)^{1 / 4}, D=E H_{\mathrm{i}}^{3} /\left(12\left(1-v^{2}\right)\right)$. The curves 2-5 differ in the wave number: $2-k=10^{-3} \mathrm{~m}^{-1} ; 3-k=0.8 \times 10^{-3} \mathrm{~m}^{-1} ; 4-k=0.6 \times 10^{-3} \mathrm{~m}^{-1} ; 5-$ $k=0.4 \times 10^{-3} \mathrm{~m}^{-1}$. Young's modulus $E=9 \mathrm{GPa}$, Poisson's ratio $v=0.33$, period of the vibrations $T=12 \mathrm{~h}$ (semi- diurnal periodicity), incoming wave amplitude $A=1 \mathrm{~m}$.

\section{TCD}

$5,2841-2863,2011$

\section{Ice shelf flexures modeled with a 2-D elastic flow line model}

Y. V. Konovalov

\section{Title Page}

\section{Abstract}

Introduction

Conclusions

References

Tables

Figures

14

$\rightarrow$

$\triangleleft$

Back

Close

\section{Full Screen / Esc}

Printer-friendly Version

Interactive Discussion 


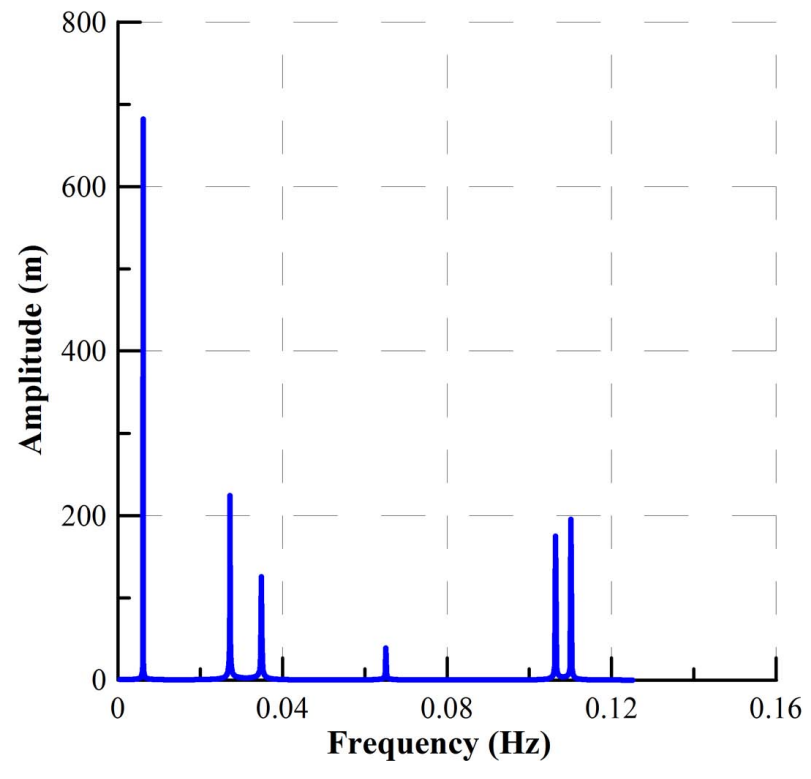

Fig. 10. Ice shelf deflections amplitude obtained in the harmonic forced vibrations problem, i.e. the Eqs. (1)-(5), (7) are solved with $-\omega^{2} \tilde{U}_{i}(x)$ instead of $\frac{\partial^{2} U_{i}(x, t)}{\partial t^{2}}$. Resonance peaks confirms that the system, which contains the glacier, the ice shelf and sub-ice-shelf sea water, has the eigenfrequencies in the considered range. The first six eigenfrequencies are $\omega_{1} \approx 0.0061 \mathrm{~Hz}$; $\omega_{2} \approx 0.027 \mathrm{~Hz} ; \omega_{3} \approx 0.035 \mathrm{~Hz} ; \omega_{4} \approx 0.065 \mathrm{~Hz} ; \omega_{5} \approx 0.106 \mathrm{~Hz} ; \omega_{6} \approx 0.11 \mathrm{~Hz}$. This eigenfrequencies appertain to the range of the periods from $250 \mathrm{~s}$ to $8 \mathrm{~s}$ that contains the frequencies of infragravity waves and ocean swells. Next six eigenfrequencies appertain to the range of the periods from $8 \mathrm{~s}$ to $3 \mathrm{~s}$. Young's modulus $E=9 \mathrm{GPa}$, Poisson's ratio $v=0.33$, ice shelf length $L_{\text {sh }}=2 \mathrm{~km}$.

\section{Ice shelf flexures modeled with a 2-D elastic flow line model}

Y. V. Konovalov

Title Page

Abstract

Conclusions

\section{Tables}

14

4

Back
Introduction

References

Figures

$\rightarrow$

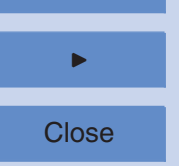

Full Screen / Esc

Printer-friendly Version

Interactive Discussion 